\title{
Vitamin D and fetal-neonatal calcium homeostasis: findings from a randomized controlled trial of high-dose antenatal vitamin D supplementation
}

\author{
Jennifer Harrington ', Nandita Perumal ${ }^{2}$, Abdullah Al Mahmud ${ }^{3}$, Abdullah Baqui ${ }^{3,4}$ and Daniel E. Roth ${ }^{1-3}$
}

BACKGROUND: There is current interest in the maternal-fetal effects of antenatal vitamin D supplementation, yet little data regarding vitamin D's role in neonatal calcium homeostasis. We determined to assess the effect of high-dose antenatal vitamin D supplementation on fetal and neonatal calcium concentrations.

METHODS: In a double-blinded, placebo-controlled trial in Bangladesh, 160 pregnant women were randomized to oral vitamin D3 $(35,000 \mathrm{IU} / \mathrm{wk})$ or placebo from 26 to $29 \mathrm{wk}$ of gestation.

RESULTS: Total serum calcium (Ca) was higher in cord blood of those supplemented vs. placebo $(2.66 \pm 0.1$ vs. $2.61 \pm 0.2 \mathrm{mmol} / \mathrm{l} ; P=0.04$ ), but the difference in albuminadjusted calcium was not statistically significant. Change in Ca concentration from birth to day 3 of life was attenuated by vitamin $D(-0.10 \pm 0.17)$ compared with placebo $(-0.22 \pm 0.18$ $\mathrm{mmol} / \mathrm{l} ; P=0.02)$. Maternal 25 -hydroxyvitamin $\mathrm{D}(25(\mathrm{OH}) \mathrm{D})$ $(P=0.04)$ and cord $25(\mathrm{OH}) \mathrm{D}(P<0.01)$ were associated with day 3 infant $C a$, suggesting that the effect of supplementation was mediated by change in maternal-infant vitamin D status. Six infants in each of the supplemented and placebo groups had transient hypercalcemia/hypercalcuria; in all the hypercalcemia/hypercalcuria was asymptomatic, spontaneously resolved, and unassociated with nephrocalcinosis at 1 mo of life.

CONCLUSION: High-dose antenatal third-trimester vitamin D supplementation attenuated the early postnatal calcium nadir, without increasing the risk of postnatal hypercalcemia.

드ss sential adaptations in maternal-fetal mineral metabolism during gestation and immediately following birth maintain a positive calcium balance for the infant (1). Vitamin D is an important factor in calcium and bone mineral metabolism, yet its role in fetal and early postnatal calcium homeostasis in humans remains unclear. Maternal vitamin D status, as measured by the major circulating metabolite 25 -hydroxyvitamin $\mathrm{D}$ $(25(\mathrm{OH}) \mathrm{D})$, is a critical determinant of fetal-neonatal vitamin $\mathrm{D}$ stores (2). Therefore, antenatal vitamin D supplementation may have important modulatory effects on fetal and neonatal calcium homeostasis.

Transplacental calcium transfer has been proposed to be independent of maternal vitamin D status (3), based on the findings of normal fetal calcium concentrations in vitamin $\mathrm{D}$ deplete rats $(4,5)$ and 1- $\alpha$-hydroxylase-deficient pigs (6). Yet, other animal models suggest a role of vitamin D; for example, antenatal 1,25 hydroxyvitamin D treatment of pregnant sheep increases fetal calcium concentration (7). In humans, evidence that vitamin D influences fetal calcium endowment emerged in several prenatal vitamin $\mathrm{D}$ trials conducted in the 1980s that demonstrated that maternal vitamin $\mathrm{D}$ supplementation in vitamin D-deficient women may increase cord serum calcium concentrations (8). Furthermore, four of these trials demonstrated a significant effect of antenatal vitamin D supplementation on infant calcium homeostasis during the first week of life (9-12). The clinical relevance of this finding was highlighted in three trials that reported decreases in the frequency of neonatal hypocalcemia $(9,10,13)$. These trial findings explained the association between low maternal 25(OH)D and increased risk of symptomatic early neonatal hypocalcemia in observational studies (14-17).

Previous trials that addressed the effects of maternal vitamin D supplementation on fetal and neonatal calcium concentrations primarily involved the use of vitamin D2 (ergocalciferol) rather than vitamin D3, employed daily doses of $1,000 \mathrm{IU}$ or less (or large single-dose regimens), and generally omitted reports of the range of serum calcium values or the occurrence of episodes of hypercalcemia (8). In light of renewed interest in the potential health benefits of vitamin D sufficiency in pregnancy, including the use of considerably higher antenatal vitamin D3 doses of 4,000-5,000 IU/d (18-20), it is of importance to assess the safety of a higher-dose regimen with respect to neonatal calcium status and, in particular, the potential risk of hypercalcemia.

The Antenatal Vitamin D in Dhaka (AViDD) trial was a randomized, placebo-controlled, double-blinded trial of weekly oral vitamin D3 (cholecalciferol) supplementation during the

\footnotetext{
Department of Paediatrics, The Hospital for Sick Children, University of Toronto, Toronto, Ontario, Canada; ${ }^{2}$ Centre for Global Child Health, The Hospital for Sick Children, Toronto, University of Toronto, Ontario, Canada; ${ }^{3}$ International Center for Diarrhoeal Disease Research, Dhaka, Bangladesh; ${ }^{4}$ International Center for Maternal and Newborn Health, Department of International Health, The Johns Hopkins Bloomberg School of Public Health, Baltimore, Maryland. Correspondence: Daniel Roth (daniel.roth@sickkids.ca) 
third trimester of pregnancy in Bangladeshi women. In this setting, low serum concentrations of $25(\mathrm{OH}) \mathrm{D}$ are common $(21,22)$, with baseline $25(\mathrm{OH}) \mathrm{D}$ concentrations of less than $50 \mathrm{nmol} / \mathrm{l}$ seen in $64 \%$ of the women recruited to AViDD (19). The aims of the present follow-up study were to expand on the current literature regarding the role of vitamin D supplementation in fetal and neonatal calcium homeostasis by: (i) estimating the effect of the prenatal vitamin D supplement on transplacental calcium flux as represented by cord calcium concentrations, (ii) characterizing the modulation of early neonatal calcium handling by prenatal vitamin $\mathrm{D}$ supplementation, and (iii) determining the safety of high-dose antenatal vitamin $\mathrm{D}$ supplementation with respect to neonatal calcium homeostasis, and, in particular, the risk of early neonatal hypercalcemia. We hypothesized that antenatal vitamin D supplementation would increase cord calcium and attenuate the postnatal drop in serum calcium concentrations without leading to an increased risk of neonatal hypercalcemia.

\section{RESULTS}

Serum specimens were obtained from 130 of 160 (81\%) mothers at the time of delivery (63 placebo and 67 vitamin D). Cord blood was collected from 67 and 65 in the placebo and vitamin D groups, respectively. Specimens were obtained from 73 (56\%) infants: 44 specimens on day 2 or 3 (36 of which were from day 3 ) and 31 specimens on days 4 to 8 (17 of which were from day 5) (Figure 1). For brevity, these two groups of time points will be referred to as "day 3" and "day 5" groups, respectively. Average maternal and cord albumin-adjusted calcium (adj-Ca) concentrations in the maternal-infant pairs with available infant biochemistry were not significantly different from those pairs for whom infant specimens were not collected (data not shown).

\section{Effect of Prenatal Vitamin D Supplementation on Transplacental} Calcium Transfer

Mean adj-Ca and mean total cord Ca concentrations were higher in the supplemented vs. the placebo group, although the difference in adj-Ca did not reach statistical difference (Table 1). Among the 127 maternal-cord pairs (63 placebo and 64 vitamin D), cord adj-Ca was independently associated with maternal adj-Ca but not with maternal or cord 25(OH)D concentrations (Table 2). Cord parathyroid hormone $(\mathrm{PTH})$ was significantly suppressed in infants born to mothers with vitamin D supplementation (Table 1). There was a significant inverse association between cord PTH and adj-Ca (Table 2).

\section{Effect of Prenatal Vitamin D Supplementation on Early Neonatal Calcium Homeostasis}

In both groups, mean adj-Ca concentrations decreased from cord blood to day 3 before rebounding at day 5 (Figure 2). There were no cases of hypocalcemia. Antenatal vitamin D supplementation was associated with higher mean infant day 3 adj-Ca concentration compared with the placebo group, with a significantly attenuated decline in adj-Ca concentration from cord to day 3 (Table 1). These findings were concordant with longitudinal analyses that demonstrated that the rate of decline in adj-Ca from birth (cord) to day 3 was significantly lower in the vitamin $\mathrm{D}$ group vs. the placebo group $(P<0.001$ for group-by-time interaction). In contrast, the rates of increase in adj-Ca beyond day 3 was similar between intervention groups $(P=0.66)$ (Supplementary Figure $\mathbf{S 1}$ online). There was no difference in serum magnesium concentrations between groups, nor was there a strong correlation between magnesium and adj-Ca concentrations (Pearson correlation $r=-0.21 ; P=$ 0.07 ). Whereas at day 3 , there was no between-group difference

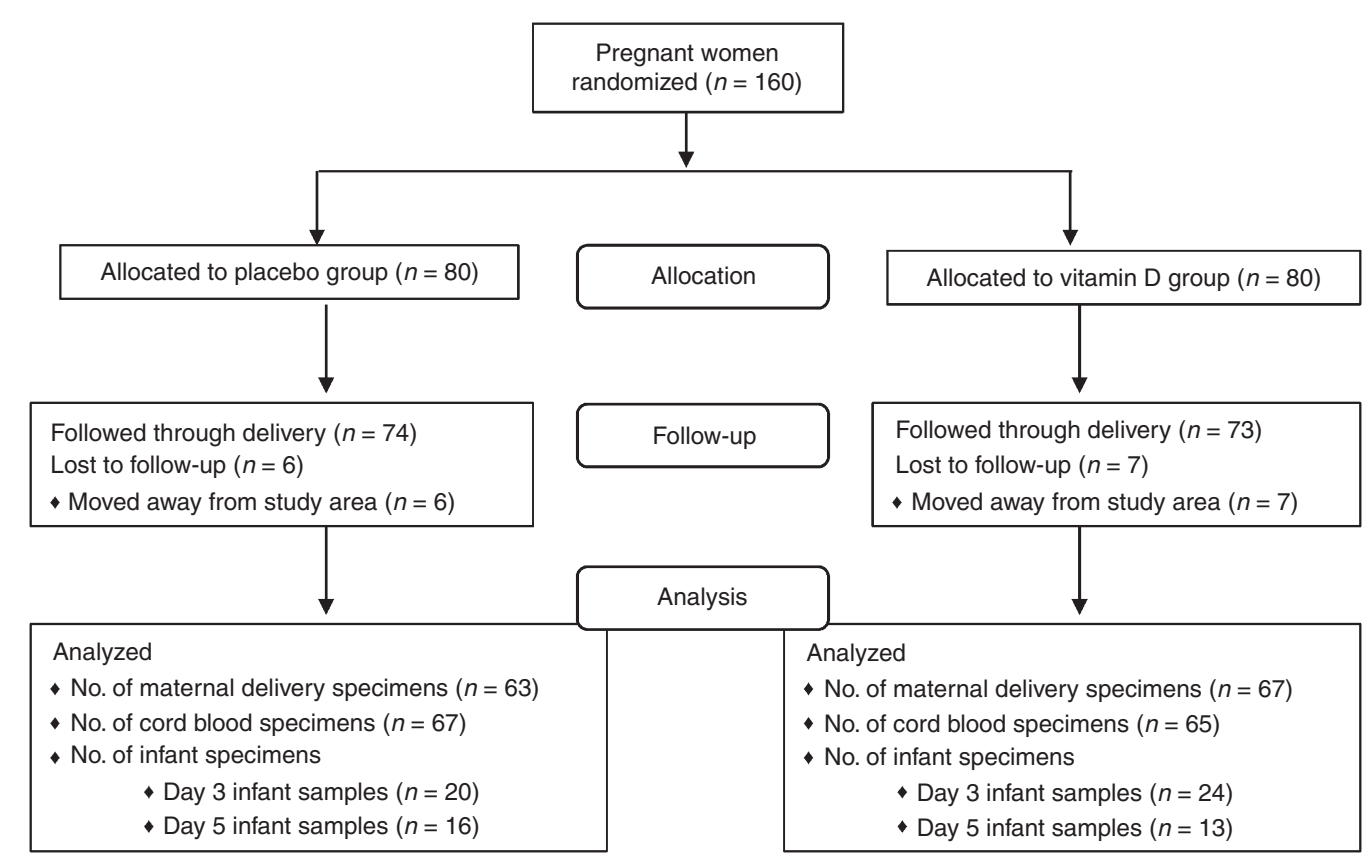

Figure 1. Allocation, follow-up, and analysis of trial participants. 
Table 1. Biochemical measurements in maternal delivery, cord, and infant blood specimens, by supplementation group

\begin{tabular}{|c|c|c|c|c|}
\hline \multirow[b]{2}{*}{ Biomarker (units) } & \multirow[b]{2}{*}{ Placebo } & \multirow[b]{2}{*}{ Vitamin D } & \multicolumn{2}{|c|}{ Group difference $^{a}$} \\
\hline & & & Mean & $95 \% \mathrm{Cl}$ \\
\hline Maternal: delivery ${ }^{b}$ & $(n=63)$ & $(n=67)$ & & \\
\hline Albumin-adjusted calcium (mmol/l) & $2.40 \pm 0.08$ & $2.43 \pm 0.09$ & $0.03^{*}$ & $(0.00,0.06)$ \\
\hline PTH $(p m o l / l)^{c, d}$ & $3.9(0.3,20.5)$ & $2.3(0.3,9.8)$ & $-0.51^{* *}$ & $(-0.8,-0.3)$ \\
\hline Cord & $(n=67)$ & $(n=65)$ & & \\
\hline Calcium (mmol/l) & $2.61 \pm 0.18$ & $2.66 \pm 0.14$ & $0.05^{*}$ & $(0.00,0.11)$ \\
\hline Albumin-adjusted calcium (mmol/l) & $2.67 \pm 0.15$ & $2.71 \pm 0.11$ & 0.04 & $(-0.00,0.09)$ \\
\hline PTH $(\mathrm{pmol} / \mathrm{l})^{\mathrm{ce} e}$ & $0.27(0.08,3.82)$ & $0.19(0.08,5.89)$ & $-0.33^{*}$ & $(-0.26,-0.02)$ \\
\hline $25(\mathrm{OH}) \mathrm{D}(\mathrm{nmol} / \mathrm{l})$ & $39.0 \pm 18.7$ & $102.8 \pm 28.6$ & $63.9^{* *}$ & $(55.8,72.0)$ \\
\hline Albumin-adjusted calcium (mmol/l/) & $2.48 \pm 0.14$ & $2.57 \pm 0.14$ & $0.10^{*}$ & $(0.01,0.18)$ \\
\hline Magnesium (mmol/l) & $0.88 \pm 0.08$ & $0.88 \pm 0.10$ & 0.00 & $(-0.06,0.06)$ \\
\hline $\mathrm{PTH}(\mathrm{pmol} / \mathrm{l})^{\mathrm{h}}$ & $6.7(1.8,10.2)$ & $5.3(2.43,7.34)$ & 0.02 & $(-0.18,0.22)$ \\
\hline Change from cord to infant day 3 & $(n=20)$ & $(n=24)$ & & \\
\hline Calcium (mmol/l) & $-0.17 \pm 0.17$ & $-0.08 \pm 0.16$ & 0.09 & $(-0.01,0.19)$ \\
\hline Albumin-adjusted calcium (mmol/l) & $-0.22 \pm 0.18$ & $-0.10 \pm 0.17$ & $0.12^{*}$ & $(0.17,0.23)$ \\
\hline Infant: postnatal day $5^{i}$ & $(n=16)$ & $(n=13)$ & & \\
\hline Calcium (mmol/l) & $2.64 \pm 0.24$ & $2.70 \pm 0.20$ & 0.06 & $(-0.11,0.23)$ \\
\hline Albumin-adjusted calcium $(\mathrm{mmol} / \mathrm{l})^{g}$ & $2.68 \pm 0.23$ & $2.74 \pm 0.18$ & 0.06 & $(-0.10,0.22)$ \\
\hline
\end{tabular}

Data are mean $\pm S D$, unless otherwise stated. ${ }^{*} P<0.05 ; * * 0.01$.

$\mathrm{Cl}$, confidence interval; $\mathrm{PTH}$, parathyroid hormone.

a Mean difference $\left(95 \% \mathrm{Cl}\right.$ ) between the placebo and vitamin D groups. bSerum samples taken from mothers at the time of delivery. ${ }^{\mathrm{M}} \mathrm{Median}$ (range) summarize PTH concentrations, due

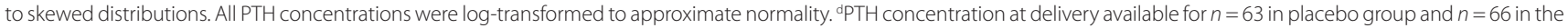
vitamin D group. ePTH concentration in cord blood available for $n=67$ in placebo group and $n=64$ in the vitamin D group. Infant: day 3 represents serum samples taken from infants at day 2 to 3 of life, with the majority of infants $(n=36)$ having a sample taken on day 3. ${ }^{9}$ Study reference range for albumin-adjusted calcium at day 3 or 5 of life: $1.9-2.82$ mmol//. hPTH concentration in infants at day 3 of life available for $n=10$ in placebo group and $n=13$ in the vitamin D group. Infant: postnatal day 5 represents serum samples taken from infants at day $4-7$ of life, with the majority of infants $(n=22)$ having a sample taken on day 5. PTH concentration in infants at day 3 of life available for $n=8$ in placebo group and $n=6$ in the vitamin D group.

in average PTH concentration, infants in the supplemented group had significantly lower PTH at day 5 (Table 1).

Among the 44 maternal-cord pairs with infant day 3 serum samples available, maternal and cord $25(\mathrm{OH}) \mathrm{D}$ concentrations were both significantly associated with infant day 3 adj-Ca, whereas cord adj-Ca and PTH were not significant predictors (Table 2). For every $10 \mathrm{nmol} / \mathrm{l}$ increase in cord 25(OH) $\mathrm{D}$, there was a $0.02 \mathrm{mmol} / \mathrm{l}$ attenuation in the decline of adj-Ca concentrations from cord to day 3 of life (95\% CI: 0.002-0.04; $P=0.03)$.

\section{Effect of High-Dose Antenatal Vitamin D Supplementation on the Risk of Early Postnatal Hypercalcemia}

Five of the 37 infants (13.5\%) in the vitamin D group and 5 of the 36 infants (13.8\%) in the placebo group were identified during the trial as having serum adj-Ca concentrations greater than the predetermined study upper reference limit of $2.82 \mathrm{mmol} / \mathrm{l}$. These 10 infants were randomly distributed throughout the range of observed maternal and cord $25(\mathrm{OH})$ D concentrations. An additional infant in each group had an isolated elevated urinary calcium:creatinine ratio $\left(\mathrm{U}_{\mathrm{Ca}: \mathrm{Cr}}\right)$ (Table 3). All infants were asymptomatic based on caregiver history, fed without difficulties, and had unremarkable clinical examinations performed by a pediatrician. Six of the $10 \mathrm{infants}$ with elevated postnatal adj-Ca concentrations had assessment of renal function based on serum creatinine and routine biochemistry, which was normal in all cases. Renal ultrasonography was performed on 11 of the 12 infants at 1 mo of age, and all had normal examinations. In all cases, there was spontaneous resolution of the elevated serum adj-Ca and $\mathrm{U}_{\mathrm{Ca}: \mathrm{Cr}}$ concentrations (Table 3). Two of the infants' parents declined further blood tests. There were no significant differences in mean maternal delivery adj-Ca or cord adj-Ca between infants who developed hypercalcemia and those who did not (Figure 3). 
Table 2. Associations of maternal and cord biochemical parameters with cord and early neonatal albumin-adjusted serum calcium concentrations

\begin{tabular}{|c|c|c|c|c|c|c|}
\hline \multirow[b]{2}{*}{ Variable (unit change) } & \multicolumn{3}{|c|}{$\begin{array}{l}\text { Cord albumin-adjusted } \\
\text { calcium }^{\mathrm{a}}\end{array}$} & \multicolumn{3}{|c|}{$\begin{array}{c}\text { Infant day } 3 \text { albumin-adjusted } \\
\text { calcium }^{\mathrm{b}, c}\end{array}$} \\
\hline & Estimate & $95 \% \mathrm{Cl}$ & $P$ & Estimate & $95 \% \mathrm{Cl}$ & $P$ \\
\hline Cord albumin-adjusted calcium (per $1 \mathrm{mmol} / \mathrm{l}$ increase) & - & - & - & -0.10 & $(-0.54,0.35)$ & 0.66 \\
\hline Maternal PTH (per 1 log pmol/l increase) ${ }^{d}$ & -0.01 & $(-0.06,0.05)$ & 0.87 & -0.07 & $(-0.20,0.07)$ & 0.32 \\
\hline Cord 25(OH)D (per $10 \mathrm{nmol} / \mathrm{l}$ increase) & 0.004 & $(0.00,0.01)$ & 0.16 & 0.02 & $(0.01,0.03)$ & $<0.01$ \\
\hline
\end{tabular}

25(OH)D, 25-hydroxyvitamin D; Cl, confidence interval.

aThis model included 127 maternal-cord pairs, 63 in the placebo group, and 64 in the vitamin D group. 'The model included 44 maternal-infant pairs, 20 in the placebo group and 24 in the vitamin D group. Infant day 3 represents serum samples collected on day 2 or 3 of life, with the majority $(n=36)$ on day $3 .{ }^{d}$ All PTH concentrations were log transformed to approximate normality.

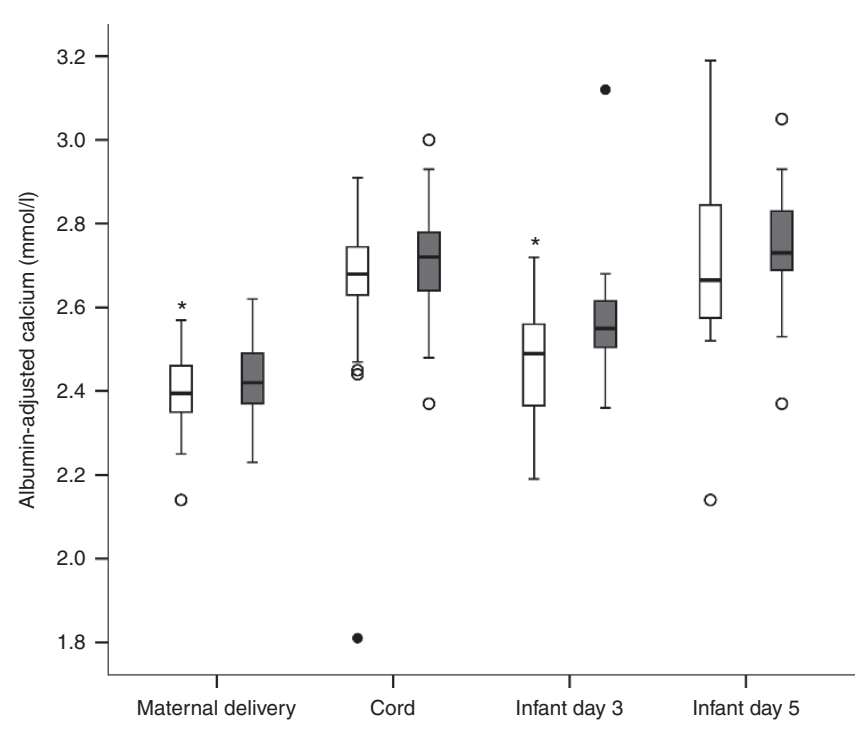

Figure 2. Albumin-adjusted serum calcium concentrations in maternal $(n=130)$, cord ( $n=132)$, and infant serum (infant day $3, n=44$; infant day $5, n=29$ ), in the vitamin D group (gray-shaded boxes) and placebo group (unshaded boxes). The black horizontal line within the box is the median, the edges of the box represent the 25 th and 75 th centiles, the caps extending from the boxes shows 1.5 times the interquartile range, and outliers are shown individually (open circles, values within 1.5 and 3 times the interquartile range; closed circles, values greater than three times the interquartile range). Asterisks $\left({ }^{*}\right)$ indicate a significant difference $(P<0.05)$ between treatment groups in albumin-adjusted calcium concentrations.

\section{DISCUSSION}

In a cohort of pregnant Bangladeshi women with a high prevalence of vitamin $\mathrm{D}$ deficiency, high-dose prenatal vitamin D supplementation $(35,000 \mathrm{IU} / \mathrm{wk})$ modulated fetal and early neonatal calcium homeostasis. Importantly, this occurred without causing an increased frequency of postnatal hypercalcemia.

The finding of higher mean cord total Ca concentration in the vitamin D-supplemented group supported the hypothesis that maternal vitamin D status influences transplacental calcium transfer. Among nine previously published antenatal supplementation trials in which cord calcium concentrations were reported (Supplementary Figure S2 online), five studies similarly found higher cord calcium concentrations with prenatal vitamin D supplementation (9,23-26). In comparison to these five studies, the four clinical trials that did not find increases in cord calcium (10-13) achieved only relatively small increases in serum 25(OH)D (with 1,000 IU of vitamin $\mathrm{D}$ or less). In fact, only the study by Delvin et al. (11) achieved a maternal 25(OH)D concentration at the time of delivery greater than $50 \mathrm{nmol} / \mathrm{l}$ in the vitamin $\mathrm{D}$-supplemented group (Supplementary Figure S2 online). From a mechanistic standpoint, the association between cord adj-Ca and maternal adjCa but not 25(OH)D concentration suggested that maternal vitamin D supplementation indirectly influenced transplacental calcium flux by increasing maternal calcium bioavailability, which is consistent with the animal literature (7).

In addition to its effects on fetal calcium homeostasis, we found that antenatal vitamin $\mathrm{D}$ supplementation also modulated early neonatal calcium homeostasis by increasing day 3 infant calcium concentration and attenuating the physiological postnatal calcium decline. These results are in accordance with all five previously published antenatal supplementation trials in which neonatal calcium concentrations were reported (9-13) (Supplementary Figure S3 online). Other than the study by Brooke et al., who reported a cord 25(OH)D concentration of $137.9 \mathrm{nmol} / \mathrm{l}$ in the vitamin D-supplemented group, the previously published trials achieved significant increases in neonatal calcium concentrations despite modest increments in cord 25(OH)D concentration of between 3.7 and $27.4 \mathrm{nmol} / \mathrm{l}$. A limitation of our study was that the infant postnatal blood specimen protocol commenced 4 mo into the trial, limiting the number of mother-infant pairs for whom postnatal biochemical data were available. The small sample size may have limited the power to detect significant associations, particularly with respect to the apparent between-group difference in infant adj-Ca at day 5. However, by assessing infant adj-Ca and PTH concentrations at two early time points, we were able to demonstrate that antenatal vitamin D supplementation not only tempered the early fall in adj-Ca concentration but also hastened recovery, as evidenced by the more rapid normalization 
Articles Harrington et al.

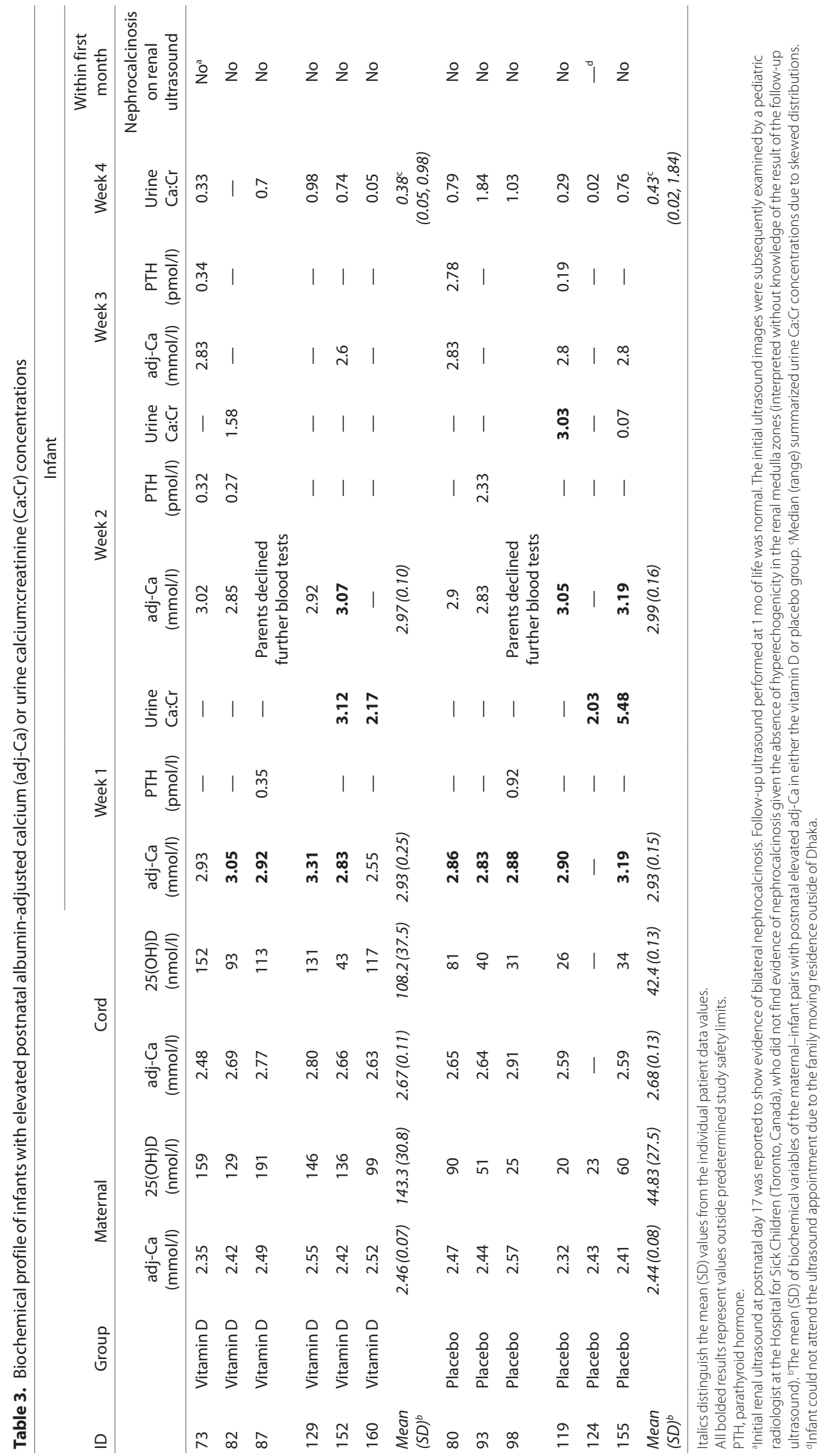




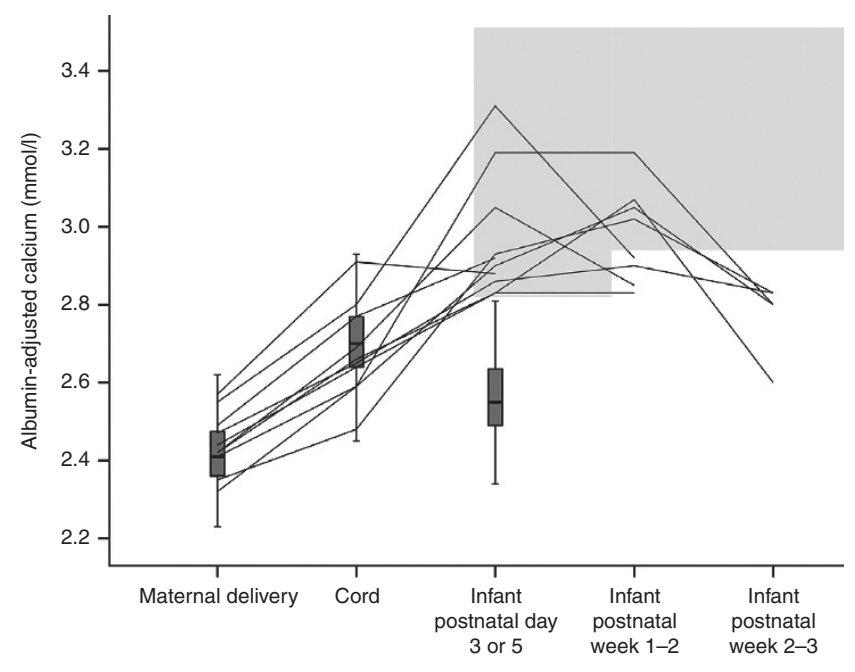

Figure 3. Maternal, cord, and infant albumin-adjusted serum calcium concentrations of infants who developed hypercalcemia. Each line shows data for an individual mother-infant pair with at least one elevated postnatal albumin-adjusted calcium concentration. Box plots represent the distribution of values among mother-infant pairs without above-range postnatal serum calcium (edges of the box represent the 25th and 75th centiles, the caps show 1.5 times the interquartile range). The shaded area represents albumin-adjusted calcium concentrations above the upper limit of the predetermined study reference range.

of infant PTH concentrations by day 5 in the supplemented group.

The strong association between cord $25(\mathrm{OH}) \mathrm{D}$ and the decline of adj-Ca from cord to day 3 suggested a postnatal effect of $25(\mathrm{OH}) \mathrm{D}$ on early infant calcium homeostasis. We speculate that the prenatally endowed pool of $25(\mathrm{OH}) \mathrm{D}$ available for activation of 1,25 hydroxyvitamin D influences the efficiency of gastrointestinal absorption of calcium and the capacity to mobilize calcium from bone. Although not measured in our subjects, antenatal vitamin D supplementation has been demonstrated to significantly increase 1,25 hydroxyvitamin D concentrations in infants (11). Since the majority of infants in the present study were breast-fed, and maternal vitamin D status does not affect breast milk calcium content (27), it is unlikely that the difference in postnatal calcium concentration between groups was attributable to differences in dietary calcium intake. There are other mechanisms that may influence calcium homeostasis that were not measured in this study. For example, common genetic polymorphisms of the vitamin $\mathrm{D}$-binding protein have been demonstrated to effect both the concentration of bioavailable $25(\mathrm{OH}) \mathrm{D}$ as well as clinical outcomes such as bone mineral density (28). However, given the ethnic homogeneity of the participants in the present study, it is unlikely that genetic factors significantly biased our results. In addition, we did not separate the C3-epimer of 25(OH)D $(\mathrm{C} 3-25(\mathrm{OH}) \mathrm{D})$ from total $25(\mathrm{OH}) \mathrm{D}$ in the present analyses. The physiological role of $\mathrm{C} 3-25(\mathrm{OH}) \mathrm{D}$ remains unclear, but we showed elsewhere that in the vitamin $\mathrm{D}$-supplemented group, an average of $10 \%$ of total cord $25(\mathrm{OH}) \mathrm{D}$ may be accounted for by C3-25(OH)D (29). Although there was a significant difference in postnatal calcium concentration between treatment groups, we did not observe any episodes of hypocalcemia. Cockburn et al. (10), who assessed 506 pregnant women assigned to receive either 0 or $400 \mathrm{IU}$ of vitamin D2, reported a lower rate of infant postnatal hypocalcemia (6 vs. 13\%) in the antenatal vitamin D-supplemented group. Symptomatic hypocalcemia in the form of hypocalcemic seizures has been reported to be associated with maternal vitamin $\mathrm{D}$ deficiency $(14,16)$, particularly in South Asia, where background rates of vitamin D insufficiency are high $(22,30)$. Attenuation in the postnatal calcium nadir with antenatal vitamin $\mathrm{D}$ supplementation could have important implications in reducing infant hypocalcemic seizure rates in high-risk populations.

Among previously published antenatal vitamin D supplementation trials in which calcium homeostasis was explored, five assessed the effect of supplementation on neonatal calcium concentrations (9-13); however, none documented either the range of postnatal calcium values or the occurrence of hypercalcemia. Therefore, an important contribution of the present study was the observation that high-dose maternal vitamin D supplementation (35,000 IU/wk) did not lead to an increased proportion of infants with elevated postnatal calcium concentrations, based on upper limits of a reference range established a priori for the study. However, the safety of high antenatal vitamin $\mathrm{D}$ doses should continue to be evaluated in future trials, given the relatively small number of infants studied and the lack of previously published data about the risk of neonatal hypercalcemia. There have been no published reports of neonatal hypercalcemia attributable to antenatal vitamin $\mathrm{D}$ supplementation in humans; however, hypercalcemia secondary to hypervitaminosis $\mathrm{D}$ has been reported in older infants given extreme doses of vitamin D (900,000-4,000,000 IU) (31) and in infants with mutations in the 1,25 hydroxyvitamin D catabolizing enzyme CYP24A1 (32). Infants in the present study who developed elevated postnatal calcium concentrations did not appear to have abnormalities in vitamin D metabolism or the calcium sensing receptor, given the transient nature of the elevation in calcium concentrations and the appropriate increase in renal calcium excretion, when measured, at the time of hypercalcemia. Instead, we believe these infants may represent the spectrum of serum calcium concentrations that can physiologically occur within the first few weeks of life and that the normal ranges for neonatal serum and urine calcium concentrations may be broader than previously recognized. The current debate regarding the serum calcium range in young infants was reflected by the recent report of Vanstone et al. (33), who reported a case of "hypercalcemia" in an infant with a peak serum calcium concentration of $2.75 \mathrm{mmol} / \mathrm{l}$ after receiving 1,400 IU of vitamin D3 for 2 mo, prompting other authors to argue that this value was well within the typical range for this age group $(34,35)$. A trial by Holmlund-Suila et al., who randomized 113 infants to receive $400,1,200$, or $1,600 \mathrm{IU} / \mathrm{d}$ of vitamin D3 from $2 \mathrm{wk}$ of life, reported that $39 \%$ of subjects had $\mathrm{U}_{\mathrm{Ca}: \mathrm{Cr}}$ greater than the study reference range of $2.2 \mathrm{mmol} / \mathrm{mmol}$, irrespective of supplementation dose or $25(\mathrm{OH}) \mathrm{D}$ concentration (36). Given the current controversies surrounding definitions of neonatal hypercalcemia and 
hypercalcuria, population-based data to inform the development of infant calcium reference ranges would enable improved safety monitoring in future prenatal and early infant vitamin D supplementation trials.

In summary, the present results support the mechanistic role of maternal prenatal vitamin D status in fetal and neonatal calcium homeostasis. In addition, this trial provides important infant safety data, demonstrating that a high-dose antenatal vitamin D supplementation regimen (35,000 IU/wk) did not increase the risk of early neonatal hypercalcemia. We conclude that high-dose antenatal vitamin $\mathrm{D}$ supplementation is likely to be safe with respect to fetal and neonatal calcium homeostasis as long as the regimen does not induce maternal hypercalcemia. These data may be used to inform the design of future trials aimed at testing current hypotheses related to the potentially broad maternal-infant health effects of improving maternal vitamin D status (37).

\section{METHODS}

Participant recruitment, randomization, and prenatal intervention in the AViDD trial have been described in detail (19). In brief, 160 healthy women, between 26 and $<30$ wk of gestation, were randomly assigned to one of two masked intervention groups: 35,000 IU of vitamin D3 (cholecalciferol) or placebo, as a weekly dose, until delivery. Vitamin D3 was delivered as a liquid formulation (Vigantol oil, 20,000 IU vitamin D3 per ml; Merck KGaA, Darmstadt, Germany), and the placebo was the oil-based vehicle lacking any vitamin D3. The dose of 35,000 IU of vitamin D3 was based on data from a pharmacokinetic study of antenatal vitamin D3 supplementation, aiming to ensure that $>90 \%$ of supplemented women achieve a $25(\mathrm{OH}) \mathrm{D}$ concentration of $>80 \mathrm{nmol} / \mathrm{l}$ by the time of delivery (38). In accordance with local standards of care, the protocol did not involve maternal or infant vitamin D supplementation in the postpartum period. Informed consent was obtained from all participants. This study was approved by ethical review boards at The Johns Hopkins Bloomberg School of Public Health (Baltimore), The Hospital for Sick Children (Toronto), and the International Center for Diarrheal Disease Research Bangladesh. The trial was registered at ClinicalTrials.gov (NCT01126528).

\section{Data Collection}

The AViDD trial was initiated in August 2010, with the first birth occurring in September 2010; however, the postnatal blood specimen collection protocol was not commenced until December 2010, thereby limiting the number of mother-infant pairs for whom postnatal biochemical data were available. The last birth occurred in April 2011. The present study was based principally on analyses of scheduled maternal venous blood collection on the day of delivery (maternal), umbilical cord venous blood (cord), and infant venous blood collection on days 3 and 5 of life. Infant specimen collection timing was chosen to capture the nadir and subsequent recovery in calcium concentrations that were expected to occur in the first week of life (1). Each individual infant had only one scheduled postnatal specimen, which was randomly assigned to be either day 3 or day 5. However, specimens could be drawn at any time during the first week depending on availability and parental preference. Specimens were assayed for serum concentrations of calcium, albumin, magnesium, PTH, and 25(OH)D. Spot urine specimens were collected from infants at the time of blood collection for the measurement of $U_{C a}$ However, infant urine collection was not routinely implemented until February 2011, after it was noted that several infants demonstrated above-range serum calcium values.

Real-time monitoring of infant postnatal serum calcium concentrations during the study was based on a study-specific algorithm adapted from published reference ranges $(39,40)$, whereby an adj-Ca concentration at day 3 or 5 of life that was $<1.90$ or $>2.82 \mathrm{mmol} / \mathrm{l}$ was considered to be outside the reference range and prompted repeat serum calcium measurement and clinical examination by a physician at about $1 \mathrm{wk}$ of life. If the serum adj-Ca was $<2.15$ or $>2.94 \mathrm{mmol} / \mathrm{l}$ on repeat assessment (39), a third blood specimen was collected in the second week of life to repeat serum calcium and other routine biochemistry (including creatinine). Infants with symptoms suggestive of hypercalcemia or hypocalcemia at any time would have prompted immediate referral to specialist care, yet no such cases occurred. Follow-up specimens were not collected for two infants, as the parents refused repeat blood collection in their well-appearing infants. Infants with urine $\mathrm{U}_{\mathrm{Ca} \text { Cr }}>2.0 \mathrm{mmol} / \mathrm{mmol}$ (41) had a repeat $\mathrm{U}_{\mathrm{CaC}}$ assessment at 1 mo of life. Renal ultrasound for assessment of possible nephrocalcinosis was scheduled at 1 mo of life for infants who had at least one above-range serum calcium or urinary $\mathrm{U}_{\mathrm{Ca:Cr}}$ values.

\section{Laboratory Analyses}

Maternal and infant venous blood specimens were collected by standard methods, and cord blood specimens were collected from the umbilical vein immediately after delivery of the placenta. Serum and urine aliquots were maintained at $4{ }^{\circ} \mathrm{C}$ and analyzed within $48 \mathrm{~h}$ of collection for serum Ca, albumin, and $\mathrm{U}_{\mathrm{Ca}: \mathrm{Cr}}$ on an AU640 Olympus Autoanalyzer (Olympus, Kobe, Japan) at International Center for Diarrheal Disease Research Bangladesh in Dhaka. Total Ca concentration was adjusted for the serum albumin concentration by the formula: $\mathrm{Ca}+(0.02 \times(40-$ albumin $))$. Intact PTH was measured at baseline and delivery using a chemiluminescent microparticle immune assay (i1000SR Architect Autoanalyzer, Abbott Park, IL) at International Center for Diarrheal Disease Research Bangladesh. Serum aliquots maintained at $-20^{\circ} \mathrm{C}$ in Dhaka were shipped at ambient temperature to Toronto for measurement of serum $25(\mathrm{OH}) \mathrm{D}$ concentration by high-performance liquid chromatography tandem mass spectroscopy (LC-MS/MS) in the Department of Pathology and Laboratory Medicine at the Hospital for Sick Children, Toronto (19).

\section{Statistical Analysis}

The primary outcome measures were: (i) cord adj-Ca (to assess the effect of maternal vitamin D supplementation on transplacental calcium transfer); (ii) infant day 3 adj-Ca and the absolute change in adj-Ca concentration from cord to day 3 of life (to define the role of prenatal vitamin D supplementation on early postnatal calcium homeostasis); and (iii) infant adj-Ca concentrations at any time, as a measure of neonatal hypercalcemia or hypocalcemia (safety assessment). For outcome 1, all available maternal and cord specimens were included in the analysis. For outcomes 2 and 3, analyses included a subset of maternal-infant pairs for which postnatal biochemical data were available. Cross-sectional between-group differences in mean serum $\mathrm{Ca}$, adj-Ca, change in adj-Ca, $\mathrm{PTH}$, and $25(\mathrm{OH}) \mathrm{D}$ concentrations were analyzed in maternal, cord, and infant specimens using unadjusted linear regression. PTH concentrations were log-transformed to approximate normality for parametric tests. The change in adj-Ca concentration from cord to infant at day 8 was also modeled longitudinally using generalized estimating equations with exchangeable correlation and robust variance estimation. Piecewise regression splines with a knot at day 3 were used in generalized estimating equations to accommodate the nonlinear change in adj-Ca with infant age. Group-by-time interaction terms were used to estimate effects of prenatal supplementation on the change in adj-Ca. To explore biological mechanisms underlying observed differences between the vitamin $\mathrm{D}$ and placebo groups, multivariable linear regression models were used to identify maternal and cord blood biochemical parameters (i.e., 25(OH)D, $\mathrm{PTH}$, adj-Ca) associated with cord adj-Ca and infant-3 adj-Ca. The placebo and vitamin $\mathrm{D}$ groups were similar with respect to baseline characteristics, including maternal vitamin D status at enrollment (19). The subjects in this study also did not differ by treatment group with respect to gestational age at delivery (placebo vs. vitamin $D$ : $39.2 \pm 2.6$ vs. $38.6 \pm 2.0 \mathrm{wk} ; P=0.14)$ or birth weight $(2,875 \pm 329$ vs. $2,975 \pm 380 \mathrm{~g} ; P=0.23$ ), and thus, these variables were not considered as mediators of the differences in biochemical parameters. 
Statistical significance was inferred with a $P$ value $<0.05$. Data were analyzed using SPSS 21.0 for windows (SPSS, Chicago, IL).

\section{SUPPLEMENTARY MATERIAL}

Supplementary material is linked to the online version of the paper at http://www.nature.com/pr

\section{STATEMENT OF FINANCIAL SUPPORT}

Financial support has been provided by Thrasher Research Fund (Salt Lake City, UT).

Disclosures: All authors have nothing to disclose.

\section{REFERENCES}

1. Salle BL, Delvin EE, Lapillonne A, Bishop NJ, Glorieux FH. Perinatal metabolism of vitamin D. Am J Clin Nutr 2000;71:Suppl 5:1317S-24S.

2. Hollis BW, Pittard WB 3rd. Evaluation of the total fetomaternal vitamin $D$ relationships at term: evidence for racial differences. J Clin Endocrinol Metab 1984;59:652-7.

3. Kovacs CS. Vitamin Din pregnancy and lactation: maternal, fetal, and neonatal outcomes from human and animal studies. Am J Clin Nutr 2008;88:520S-8S.

4. Miller SC, Halloran BP, DeLuca HF, Jee WS. Studies on the role of vitamin $\mathrm{D}$ in early skeletal development, mineralization, and growth in rats. Calcif Tissue Int 1983;35:455-60.

5. Brommage R, DeLuca HF. Placental transport of calcium and phosphorus is not regulated by vitamin D. Am J Physiol 1984;246(4 Pt 2):F526-9.

6. Lachenmaier-Currle U, Harmeyer J. Placental transport of calcium and phosphorus in pigs. J Perinat Med 1989;17:127-36.

7. Durand D, Braithwaite GD, Barlet JP. The effect of 1 alpha-hydroxycholecalciferol on the placental transfer of calcium and phosphate in sheep. Br J Nutr 1983;49:475-80.

8. RothDE. Vitamin D supplementation duringpregnancy: safety considerations in the design and interpretation of clinical trials. J Perinatol 2011;31:449-59.

9. Brooke OG, Brown IR, Bone CD, et al. Vitamin D supplements in pregnant Asian women: effects on calcium status and fetal growth. Br Med J 1980;280:751-4.

10. Cockburn F, Belton NR, Purvis RJ, et al. Maternal vitamin D intake and mineral metabolism in mothers and their newborn infants. Br Med J 1980;281:11-4.

11. Delvin EE, Salle BL, Glorieux FH, Adeleine P, David LS. Vitamin D supplementation during pregnancy: effect on neonatal calcium homeostasis. J Pediatr 1986;109:328-34.

12. Zeghoud F, Garabedian M, Jardel A, Bernard N, Melchior J. [Administration of a single dose of 100,000 U.I. of vitamin D3 in the pregnant woman in winter. The effect on blood calcium level of the newborn infant]. J Gynecol Obstet Biol Reprod (Paris) 1988;17:1099-105.

13. Mallet E, Gügi B, Brunelle P, Hénocq A, Basuyau JP, Lemeur H. Vitamin D supplementation in pregnancy: a controlled trial of two methods. Obstet Gynecol 1986;68:300-4.

14. Teaema FH, Al Ansari K. Nineteen cases of symptomatic neonatal hypocalcemia secondary to vitamin D deficiency: a 2-year study. J Trop Pediatr 2010;56:108-10.

15. Ashraf A, Mick G, Atchison J, Petrey B, Abdullatif H, McCormick K. Prevalence of hypovitaminosis D in early infantile hypocalcemia. J Pediatr Endocrinol Metab 2006;19:1025-31.

16. Mehrotra P, Marwaha RK, Aneja S, et al. Hypovitaminosis d and hypocalcemic seizures in infancy. Indian Pediatr 2010;47:581-6.

17. Thomas TC, Smith JM, White PC, Adhikari S. Transient neonatal hypocalcemia: presentation and outcomes. Pediatrics 2012;129:e1461-7.

18. Hollis BW, Johnson D, Hulsey TC, Ebeling M, Wagner CL. Vitamin D supplementation during pregnancy: double-blind, randomized clinical trial of safety and effectiveness. J Bone Miner Res 2011;26:2341-57.

19. Roth DE, Al Mahmud A, Raqib R, et al. Randomized placebo-controlled trial of high-dose prenatal third-trimester vitamin D3 supplementation in Bangladesh: the AViDD trial. Nutr J 2013;12:47.
20. Dawodu A, Saadi HF, Bekdache G, Javed Y, Altaye M, Hollis BW. Randomized controlled trial (RCT) of vitamin D supplementation in pregnancy in a population with endemic vitamin D deficiency. J Clin Endocrinol Metab 2013;98:2337-46.

21. Islam MZ, Shamim AA, Kemi V, et al. Vitamin D deficiency and low bone status in adult female garment factory workers in Bangladesh. Br J Nutr 2008;99:1322-9.

22. Islam MZ, Lamberg-Allardt C, Kärkkäinen M, Outila T, Salamatullah Q, Shamim AA. Vitamin D deficiency: a concern in premenopausal Bangladeshi women of two socio-economic groups in rural and urban region. Eur J Clin Nutr 2002;56:51-6.

23. Congdon P, Horsman A, Kirby PA, Dibble J, Bashir T. Mineral content of the forearms of babies born to Asian and white mothers. Br Med J (Clin Res Ed) 1983;286:1233-5.

24. Marya RK, Rathee S, Dua V, Sangwan K. Effect of vitamin D supplementation during pregnancy on foetal growth. Indian J Med Res 1988;88:488-92.

25. Marya RK, Rathee S, Lata V, Mudgil S. Effects of vitamin D supplementation in pregnancy. Gynecol Obstet Invest 1981;12:155-61.

26. Hashemipour S, Lalooha F, Zahir Mirdamadi S, Ziaee A, Dabaghi Ghaleh T. Effect of vitamin $\mathrm{D}$ administration in vitamin $\mathrm{D}$-deficient pregnant women on maternal and neonatal serum calcium and vitamin D concentrations: a randomised clinical trial. Br J Nutr 2013;110:1611-6.

27. Basile LA, Taylor SN, Wagner CL, Horst RL, Hollis BW. The effect of highdose vitamin D supplementation on serum vitamin D levels and milk calcium concentration in lactating women and their infants. Breastfeed Med 2006;1:27-35.

28. Powe CE, Evans MK, Wenger J, et al. Vitamin D-binding protein and vitamin D status of black Americans and white Americans. N Engl J Med 2013;369:1991-2000.

29. Bailey D, Perumal N, Yazdanpanah M, et al. Maternal-fetal-infant dynamics of the C3-epimer of 25-hydroxyvitamin D. Clin Biochem 2014;47: $816-22$.

30. Sachan A, Gupta R, Das V, Agarwal A, Awasthi PK, Bhatia V. High prevalence of vitamin D deficiency among pregnant women and their newborns in northern India. Am J Clin Nutr 2005;81:1060-4.

31. Joshi R. Hypercalcemia due to hypervitaminosis D: report of seven patients. J Trop Pediatr 2009;55:396-8.

32. Schlingmann KP, Kaufmann M, Weber S, et al. Mutations in CYP24A1 and idiopathic infantile hypercalcemia. N Engl J Med 2011;365:410-21.

33. Vanstone MB, Oberfield SE, Shader L, Ardeshirpour L, Carpenter TO. Hypercalcemia in children receiving pharmacologic doses of vitamin D. Pediatrics 2012;129:e1060-3.

34. Fischer PR, Oberhelman SS, Raumann NA, Singh RJ, Thacher TD. Definition of "hypercalcemia" in infants. Pediatrics 2012;129.

35. Taylor SN, Wagner CL, Shary J, Hollis BW. Defining hypervitaminosis D in children. Pediatrics 2012;129.

36. Holmlund-Suila E, Viljakainen H, Hytinantti T, Lamberg-Allardt C, Andersson S, Mäkitie O. High-dose vitamin d intervention in infantseffects on vitamin d status, calcium homeostasis, and bone strength. J Clin Endocrinol Metab 2012;97:4139-47.

37. Hollis BW, Wagner CL. Vitamin D and pregnancy: skeletal effects, nonskeletal effects, and birth outcomes. Calcif Tissue Int 2013;92:128-39.

38. Roth DE, Al Mahmud A, Raqib R, Akhtar E, Black RE, Baqui AH. Pharmacokinetics of high-dose weekly oral vitamin D3 supplementation during the third trimester of pregnancy in Dhaka, Bangladesh. Nutrients 2013;5:788-810.

39. Ghoshal AK, Soldin SJ. Evaluation of the Dade Behring Dimension RxL: integrated chemistry system-pediatric reference ranges. Clin Chim Acta 2003;331:135-46.

40. Nelson N, Finnström O, Larsson L. Neonatal reference values for ionized calcium, phosphate and magnesium. Selection of reference population by optimality criteria. Scand J Clin Lab Invest 1987;47:111-7.

41. So NP, Osorio AV, Simon SD, Alon US. Normal urinary calcium/creatinine ratios in African-American and Caucasian children. Pediatr Nephrol 2001;16:133-9. 